\title{
O Servidor Público na Legislação do Primeiro Reinado
}

\section{Domingos Carvalho da Silva}

\section{Escritor e Professor universitário (UnB)}

Em termos de esquema, pode ser dito que a legislação sobre o funcionalismo público brasileiro, no regime inaugurado pelo grito de 7 de setembro de 1822 e encerrado pela abdicação do imporador, se equilibra em dois suportes básicos: a Constituição de 1824 e o Código Criminal de 1831. Fora de tais leis o que houve, com poucas exceções, foi a criação de cargos públicos com os respectivos ordenados ou vencimentos e, às vezes, com a definição de atribuições.

Essa praxe não se amoldava a nenhum sistema. Cada vez que fosse necessário criar e prover um cargo, ou prover cargo já existente, era expedido o competente decreto, ou decisão, ou mesmo uma simples carta imperial. 0 cargo era citado e o provimento era feito como hole habitualmente ocorre numa empresa privada: se há necessidade de um arquivista, manda-se admiti-lo e inclui-lo na folha de pagamento. Era, aparentemente, este o "sistema" adotado nas repartiçöes civis do Poder
Executivo. Em poucas havia uma relação de cargos e nada disciplinava, quanto ao valor dos ordenados, ao acesso a funçöes mais elevadas, etc., os direitos de titulares de cargos semelhantes, distribuidos por diferentes repartições.

A situação nos quadros militares era diferente, em decorrência da natureza das suas funçōes. A tropa tinha uma organização e uma disciplina adequadas à sua atividade nos quartéis e em campanha. Para servir os capitães-generais, os coronéis e os alferes eram, porém, necessários oficiais civis (oficiais eram chamados todos os servidores públicos de boa categoria), tais como tesoureiros, escriturários e amanuenses. Nas repartições militares os empregados civis - pelo menos os de escalão médio e superior - também usavam uniforme, embora com insignias diferentes das dos oficiais da tropa.

Nas repartiçōes judiciais ("Do Poder Judicial", e não Judiciário como agora, R. Serv. Públ., Brasília, 108 (1): jan/abr. 1973 
tratava o Capítulo VI da Constituição), também havia certa uniformidade na distribuição de cargos e na retribuição salarial, graças à especialização e à geral vitaliciedade da maioria das funçōes. Os cargos ordinariamente existentes eram os de juiz, procurador, escrivão, amanuense, meirinho e contínuo. Escrivães e amanuenses eram, na nomenclatura forense, oficiais de justiça, pois esta expressão não tinha ainda a restrita significação atual.

Fora das repartições militares ou forenses os cargos, já dissemos, eram criados de acordo com as conveniências ou oportunidades, pertencessem eles à Assembléia Legislativa Geral ou à Intendência de Polícia, à Alfândega da Bahia ou à Biblioteca Imperial e, não raro, com a expedição do regimento de uma repartição qualquer, no corpo dęuma tabela sumária.

Nos primeiros anos do Império era - imperador quem criava e preenchia os cargos públicos em todo o país. Todavia a primeira referência da Constituição a tais cargos (art. 15, parágrafo XVI) declara ser "atribuição da Assembléia Geral" - criar ou suprimir empregos públicos, e estabelecer-lhes ordenados". Este dispositivo, porém, nem sempre foi cumprido, ou por não estar reunida a Assembléia, ou por exorbitância do imperador.

\section{PASSOS INICIAIS}

Do grito do Ipiranga ao juramento da Constituição do Império correm dezoito meses durante os quais são, na verdade, dados os primeiros passos para a organização administrativa do pais, atingindo, direta ou indiretamente, todos os setores do serviço público civil. Não ocorre porém qualquer delenda Carthago: o Brasil passa à condição de Império pelas mãos do mesmo grupo de homens que o dirigia quando Reino Unido. A máquina administrativa não pára, nem encontra obstáculos além da resistência militar portuguesa. Onde essa resistência controla o poder político as repartições obedecemIhe. Mas, na medida em que as províncias vão aderindo à independência, essas repartiçరes vão-se integrando pacificamente na Administração central. Não há portanto necessidade imediata de reformular, de reorganizar, mesmo porque assuntos de natureza mais urgente empolgam todas as energias do Governo.

O primeiro cargo público civil criado no novo Império foi, ao que parece, - de bibliotecário da Biblioteca Pública da Corte, assim denominada no decreto de 23-10-1822, do imperador aclamado. Para esse cargo D. Pedro nomeou frei Antônio de Arrábida, que era seu confessor.

Em 4 de fevereiro de 1823 é criada, por decreto, na Mesa do Consulado (dependência da Secretaria da Fazenda) uma Administração para a Arrecadação de Diversas Rendas. $O$ decreto enumera uma relação de cargos nevos: além do Administrador, um escrivão, um tesoureiro, quatro escriturários, dois amanuenses, agentes em número não expresso e guardas. No dia seguinte sai outro decreto fixando os vencimentos dos ocupantes de alguns desses cargos: o escrivão e o tesoureiro vão ganhar um conto de réis por ano; os 
escriturários, trezentos mil réis cada um.

Em 24 de abril sai um decreto pelo qual se organiza o pagamento dos ordenados do corpo diplomático. E, entre vários atos destinados a criar cargos de professores de primeiras letras, chama a atenção o decreto de 16 de agosto, pelo qual é criado "um lugar de intérprete de francês e inglês na Intendência Geral de Polícia", com ... $300 \$ 000$ Rs. anuais de ordenado.

Não faltavam, em 1823, dúvidas quanto ao critério a seguir no caso da aplicação da legislação portuguesa no Brasil. Um decreto de 22 de outubro daquele ano dirimiu tais dúvidas, declarando em vigor a legislação pela qual se regia $\circ$ Brasil até 25-4-1821 (data da partida de D. João VI) e as leis promulgadas por D. Pedro daquela data em diante, e ainda determinados decretos das Cortes Portuguesas, expedidos entre 25-4-1821 e 7-9-1822. Graças a esse ato juridico continuava em vigor no Império, salvo naquilo em que tivesse sido expressamente revogada, a legislação civil, criminal, processual, fiscal e administrativa portuguesa, e com ela as leis referentes aos servidores do Estado.

Da mesma data dessa importante decisão é a lei que impedia os deputados à Assemblóia Geral Constituinte, então reunida, de exercerem qualquer outro emprego (público) durante a sua deputação, de pleitear empregos para terceiros, benefícios etc. Essa lei enumerava exceção que favoreciam os ministros e secretários de Estado, o in- tendente geral de Policia e certos servirores graduados.

Em contraste com o ínfimo número de atos referentes ao pessoal civil, foi copiosa, de setembro de 1822 a março de 1824 , a quantidade de decisões e decretos relativos ao pessoal militar. As razões são bem claras: a sobrevivência do novo Estado dependia principalmente da organização e da ação do Exército e da Marinha de Guerra.

\section{POLITICA E SERVIÇÓ PÚBLICO}

A Constituição jurada em 25 de março de 1824 não se preocupa muito com os servidores de médio ou pequeno escalão: nos poucos artigos em que trata dos empregados do Estado, cuida quase exclusivamente dos eleitos para a Assembléia Geral e dos nomeados para o corpo diplomático ou para funçōes judiciais, e que constituem, naturalmente, o escol da burocracia.

Vejam-se as relações previstas na citada Carta entre o serviço público e a função política: o art. 32 determina a cessação interina do exercicio de "qualquer emprego" (público, naturalmente, de acordo com o critério do léxico constitucional) "enquanto durarem as funçōes de deputado ou senador"; o artigo 33 proíbe que, no intervalo das sessões legislativas, o imperador conceda, a parlamentares, empregos no exterior; e proibe também a estes a volta às províncias, para o exercicio de seus cargos (públicos), durante tais intervalos, "quando isso os impossibilite para se reunirem no tempo da convocação da Assembléia 
geral ordinária ou extraordinária". É fácil ver que esta proibição cria discriminaçōes entre os parlamentares funcionários: os que moram na Corte ou redondezas podem exercer seus empregos nos intervalos das sessões; os outros não podem.

A Constituição volta a mencionar os empregados públicos no art. 92, parágrafo III, que proibe aos filhos-famílias o exercício do voto nas eleições primárias, "salvo se servirem ofícios públicos". As razões da proibição e da exceção são coerentes: no sistema constitucional era necessário ter uma renda minima para ser eleitor de paróquia. Os filhos-familias, embora fiIhos de pais ricos, viviam à custa destes e não tinham, portanto, renda pessoal. Não podiam votar. Mas, se exercessem um cargo público que lhes desse uma renda anual de cem mil réis, Já seriam eleitores.

O sistema de eleição dos deputados à Assembléia Geral e da escolha dos candidatos ao Senado era indireto: os eleitores de paróquia escolhiam, nas eleiçõęs primárias, seus representantes, isto é, os eleitores dos deputados e dos integrantes dås linhas tríplices de candidatos ao Senado. Para ser eleitor de paróquia bastava auferir a citada renda anual de $100 \$ 000$ Rs. Para ser votado e, portanto, para ser eleitor de província, era exigida a renda de $200 \$ 000$ Rs.. que só excluia do processo eleitoral os empregados públicos mais humildes.

O empregado civil que pudesse ser eleitor de província poderia também ser eleito membro do Conselho Regio- nal da Província, antecessor da Assembléia Legislativa provincial, desde que tivesse vinte e cinco anos de idade, probidade e a "decente subsistência" (art. 75) que os duzentos mil réis anuais asseguravam. Mas para ser deputado geral ou senador era preciso auferir, em atividades privadas ou funçőes públicas, a renda mínima anual de $400 \$ 000$ Rs. (art. 95), que não era rara entre os oficiais civis de segundo escalão: o ordenado de cinqüenta ou sessenta mil réis mensais era comum.

O mesmo art. 95 proibia a eleição dos não católicos (certamente não os havia entre os servidores públicos, obrigados a jurar a Constituição católica) e, para a Câmara dos Deputados, dos naturalizados. Convém lembrar porém que os naturais de Portugal que tivessem aderido, mesmo tacitamente, à independência, eram considerados brasileiros com direitos em tudo iguais aos dos aqui nascidos.

\section{MAGISTRADOS E DIPLOMATAS}

O art. 101 da Constituição atribui competência ao imperador para, no exercício do poder moderador, suspender de suas funções os magistrados, no caso de queixas contra eles apresentadas (art. 154). O parágrafo III do art. 102 atribui-Ihe, como Chefe do Executivo, o poder de nomeá-los. O parágrafo IV do mesmo art. 102 atribui ao imperador competência para "prover os mais empregos civis e politicos" e o parágrafo VI confere-lhe poderes para "nomear embaixadores, e mais agentes diplomáticos e comerciais". Essas nomeações dependiam porém de audiência do Conselho de Estado, na forma do art. 142. 
A partir do art. 151 trata a Constituição dos juizes e tribunais de justiça e da responsabilidade dos magistrados e serventuários. A demissão de juizes depende de sentença judicial (art. 155). O artg. 156 responsabiliza juizes e oficiais de justiça (serventuários em geral) "pelos abusos de poder e prevaricações" e o artigo seguinte, por suborno, peita, peculato e concussão. Com base no art. 157, além do prejudicado, qualquer do povo pode propor contra os magistrados a ação popular destinada à sua punição. Dos catorze artigos da Carta sobre o Poder Judicial, cinco contêm disposições referentes a delitos de magistrados e sua punição.

0 art. 179 conclui as referências da Constituição aos funcionários. Declara ele, no parágrafo XIV, que "todo o cidadão pode ser admitido aos cargos públicos civis, políticos ou militares, sem outra diferença que não seja a dos seus talentos e virtudes." O parágrafo XXIX do mesmo artigo torna claro que os empregados públicos "são estritamente responsáveis pelos abusos e omissões praticados no exercício de suas funções" etc.

\section{MARCHA PARA UM SISTEMA}

A criação e o provimento dos cargos públicos, bem como a fixação dos respectivos ordenados, salários ou vencimentos são, nos primeiros anos do Império, atos do arbítrio do imperador, e por isso alheios a qualquer sistema, salvo, como Já dissemos, os que se relacionam com a carreira militar e o poder Judiciário. Instalada porém a Assembléia Geral, começa a sua faina para estabelecer no país uma estrutura jurídica capaz de organizá-lo como um todo. Uma das tendências dos legisladores gerais é a descentralização administrativa: as leis que vão sendo promulgadas fazem com que escape, dia a dia, das mãos do imperador, um pouco do seu poder inicial. Outra obra importante da Assembléia é a organização de uma burocracia nacional e provincial (e mesmo municipal) que vai constituir no pais, se não uma classe social, pelo menos um grupo profissional numeroso e empenhado na estabilidade e no equilibrio das instituições legais.

A formaçăo dessa burocracia vai surgindo através de sucessivas medidas cuja enumeração cronológica seria, além de impraticável, inconveniente a uma visão geral do problema. Optamos pelo exame de alguns pormenores, de certos deveres, garantias e direitos que vão sendo instituídos, de tal sorte que em 1831, ano da abdicação, aquilo que, nove anos antes, era a desarticulação e o improviso, já se apresenta como um começo de sistema.

Entre os direitos, garantias, instituições e deveres que podem ser relacionados, arrolamos, sem a ambição de levantamento total, os seguintes: a) criação, provimento, extinção, tabelas e denominação dos cargos públicos; b) ordenados, salários, vencimentos e gratificações de servidores; c) direitos dos servidores: vitaliciedade, substituiçăo, acesso, "disponibilidade", acumulação, igualdade de salários, aposentadoria; d) deveres: o juramento, a assituidade, a pontualidade; e) responsa- 
bilidade dos servidores: desconto, repreensão, suspensão, demissão, responsabilidade penal. Destes temas cuidaremos nos parágrafos seguintes.

\section{CARGOS PÚBLICOS E TABELAS}

Da decisão de 22-2-1823, que aprovava instruçōes para a escrituraçăo da arrecadação do Hospital Militar da Corte, constava a relação dos cargos exercidos pelos servidores daquele nosocômio oficial. Entre outros cargos havia os de almoxarife, fiel, escrivão, boticário, enfermeiro e cozinheiro. Graças a essa e a outras relações posteriores, é possivel elaborar uma lista, embora incompleta, das funções exercidas pelos empregados civis das repartições militares, das repartições do Executivo e do Judiciário, excluídos das últimas os magistrados. Segue abaixo a lista:

\section{Administrador - Agente - Ajudante - Ajudante de Bibliotecário - Aju-} dante de Enfermeira - Ajudante de Enfermeiro - Almoxarife - Amanuense - Apontador - Bibliotecário Boticário - Capelão - Chefe de Departamento - Cirurgião - Comissário - Comprador - Contador - Contador Geral - Continuo - Correio Corretor - Cozinheiro - Diretor - Enfermeira - Enfermeiro - Encarregado de Escrituração - Escriturário Escrivão - Feitor - Fiel - Fisico Guarda - Intérprete - Jardineiro Livreiro Encadernador - Meirinho Médico - Oficial - Oticial Ajudante - Oficial Papelista - Porteiro - Pagador - Praticante - Praticante de Boticário - Primeiro Cirurgião - Primeiro Escriturário - Primeiro Médico - Professor de Phimeiras Letras R. Serv. Públ., Brasilia, 108 (1): jan/abr. 1973
Professor de Latim - Professor de Português - Secretário - Segundo Escriturário - Servente - Terceiro Escriturário - Tesoureiro.

Muitas das denominações acima são genéricas. Na prática os cargos tinham denominações especificas ou restritivas como Escrivão da Intendência, $\mathrm{Pa}$ gador da Marinha ou Escrivão do Hospital. Havia também cargos iguais com denominações diversas, como os de Praticante de Boticário e Praticante do Laboratório da Botica. Havia Enfermeiros e Enfermeiras para pacientes masculinos ou femininos. Havia Oficiais e Fiéis com as mais variadas especializaçöes.

O Regimento Interno da Biblioteca Imperial e Pública da Corte (13-9-1824), o primeiro expedido pelo imperador, enumerava os cargos dos doze empregados daquela instituição (um bibliotecário-diretor, um ajudante de bibliotecário, três oficiais ajudantes, dois amanuenses, quatro serventes e um Iivreiro encadernador) e, de modo pouco preciso, as respectivas atribuiçōes. Além desses servidores havia dois escravos cujos serviços eram pagos a seus senhores. Entretanto, por ato de 23 de março do ano seguinte, o imperador mandou comprar oito escravos para o serviço do Jardim Botânico.

Um decreto pouco posterior, de 18 de maio, traz uma referência aos extranumerários, sem esclarecer o seu regime de admissão e pagamento. Esse ato do Governo, que igualou os saláros dos escriturários da Contadoria de Marinha aos dos oficiais do Tesouro Nacional, menciona os "Praticantes 
do número e Extranumerários da mesma Contadoria".

A criação de cargos públicos e o seu provimento é causa de uma permanente disputa velada e, em certa ocasião, ostensiva, entre o imperador e a Assembléia, Muito embora depois de promulgada a Constituição a criação de cargos competisse ao Legislativo, o seu provimento continuava a ser atribuição de D. Pedro. Entretanto, pelo menos a partir de 1826, leis elaboradas pela Assembléia iam aos poucos alterando tal situação. A lei de 27 de agosto daquele ano, que "Dá Regimento para os Conselhos Gerais de Província", atribui competência aos presidentes das províncias para a nomeação dos quatro empregados de cada Conselho (um oficial para o expediente, um porteiro e dois ajudantes). A lei de 15-12-1830, que aprova o orçamento para o ano financeiro de $1831 / 32$, proibe, num de seus artigos, a criação de novos cargos públicos, salvo pela Assembléia Geral, o que é redundante: pela Constituiçăo só a Assembléia poderia criá-los.

A mesma lei orçamentária extingue e cria cargos e altera os vencimentos de outros. A prática de extinguir cargos por lei, imposta pela Assembléia, é uma decorrência de artigo constitucional já citado no presente estudo.

Outra prática de alta importância e conveniência, adotada pela Assembléia Geral, é a de incluir, nos regimentos das dependências públicas, capítulos referentes às funçöes e responsabilidades dos respectivos servidores. 0 primeiro diploma legal em que encontramos um capítulo separado, com relação dos cargos de uma instituição e a definição das atribuições e dos deveres dos empregados, é a lei de 27 de agosto de 1828 (Regimento dos Conselhos de Província). Segue-Ihe 0 exemplo a lei de 18 de setembro do mesmo ano, que cria o Supremo Tribunal de Justiça. O capítulo III dessa lei trata "Dos Empregados do Tribunal", que são cinco: um secretário, um tesoureiro, dois continuos e um oficial de secretaria.

\section{VENCIMENTOS E GRATIFICAÇŌES}

A leitura dos atos públicos referentes ao pagamento dos serviços prestados não esclarece a diferença de conceito entre salário, ordenado e vencimento. O militar, é claro, percebe o soldo e o eclesiástico percebe as côngruas. Os civis percebem quase sempre o ordenado, além das gratificações, que não são raras.

A palavra vencimentos aparece já no decreto de 21-8-1824, cuja ementa (segundo as "Leis do Brasil") é esta: "Marca provisoriamente os vencimentos dos empregados da Biblioteca Imperial e Pública". Todavia um decreto de 17-2-1825 aumenta "os ordenados dos magistrados"; uma decisão do dia seguinte menciona "o novo ordenado" dos empregados públicos quando passarem "a ocupar outro lugar de maior vencimento". Um decreto de 18-5,-1825 iguala os "salários dos $2^{\circ} \mathrm{s}$ e $3^{\circ} \mathrm{s}$ escriturários da Marinha a oficiais do Tesouro de igual denominação"; uma decisão de 16-9-1826 refere-se ao vencimento dos aposentados; uma carta im- 
perial de 19-8-1825 nomeia um professor e fixa-lhe o ordenado; pela decisão de 14-3-1825 é aprovada a Tabela de Vencimentos dos oficiais civis do Arsenal da Marinha da Bahia; um assomo feminista determina, no art. 13 da lei de 15 de outubro de 1827, que ¿s "mestras vencerão os mesmos ordenados e gratificações concedidos aos mestres".

Não é fácil saber agora a significação do valor, no primeiro reinado, de um salário anual de duzentos ou trezentos mil réis. A desvalorização da moeda fazia com que, de ano para ano, caisse um pouco o seu poder aquisitivo. E como para ser eleitor de paróquia era necessária um renda anual mínima de $100 \$ 000$ Rs, o direito de voto cobria, em cada nova eleição, uma área mais ampla.

Os cargos mais altos eram evidentemente rendosos, e por isso muitos deles eram comprados pelos seus titulares. Havia cargos vitalicios, cargos de "propriedade", cargos arrendados e contratados, o que estava de acordo com a tradição colonial dos contratadores dos dizimos, dos diamantes ou da pesca da baleia, em alguns casos semelhantes aos atuais concessionários dos serviços públicos. A diferença fundamental está em que estes modernos concessionários não "compram" a execução dos serviços: apenas pagam impostos.

A lei de 15-9-1827, que extinguiu os lugares de Intendente Geral do Ouro no Rio e na Bahia, determinou que "aos escrivães e meirinhos, proprietários ou vitalicios", fossem conser- vados os ordenados. Logo lepois a lei de 11-10-1827 configurava a "forma porque devem ser providos os oficios da Justiça e Fazenda". Nos termos dessa lei o servidor vitalício impossibilitado (por doença ou idade) de exercer o cargo era obrigado a cedê-lo a outra pessoa, que o compraria pelo terço do valor; morrendo o titular (cedente), decaía o direito do cessionário que, se quisesse manter-se no cargo, teria que comprá-lo de novo.

Havia por certo muitos interessados nos bons cargos que, dando boa renda, abriam, ipso facto, o ingresso na carreira politica. Em 1825 um almoxarife do Exército ganhava anualmente $400 \$ 000 R s$. renda minima para um candidato a deputado. Com uma renda de $200 \$ 000$ Rs por ano um escrivão podia ser, além de eleitor de provincia, vereador municipal ou membro do Conselho Geral da província em que morasse. Mas um fiel, com os seus $60 \$ 000 \mathrm{Rs}$, não teria sequer direlto de votar na sua paróquia. $O$ boticário do Hospital de S. Pedro de Alcântara, em Goiás, com os seus duzentos e cinqüenta mil réis por ano, também poderia chegar ao Conselho da Província. Mas o diretor do mesmo hospital, com os seus $120 \$ 000 \mathrm{Rs}$, não iria além de eleitor de paróquia. Os enfermeiros, com $80 \$ 000$ Rs, e os seus ajudantes, com a metade, Jamais teriam "decente subsistência" para exercer o direito de voto.

No Exército os soldos, sem as gratificações, variavam muito: um tenente ganhava apenas $300 \$ 000$ Rs por ano (o porteiro da Faculdade de Direito de São Paulo ganhava, em 1828, 400\$000); 
um coronel ganhava $840 \$ 000$ Rs e um marechal do Exército, 2:400\$000 Rs. 1:200\$000 Rs. e 1:950\$000 variavam os Os magistrados ganhavam bem: entre salários dos ouvidores, desembargadores e chanceleres do Rio e da Bahia.

Uma resolução de julho de 1827 , da Assembléia Geral, igualou em $150 \$ 000$ Rs os ordenados dos professores de primeiras letras e, algum tempo depois esse beneficio era estendido aos de latim. Mas tais salários eram de tal modo insuficientes, que uma lei de 15 de outubro do mesmo ano os fixou entre duzentos e quinhentos mil réis, cabendo o arbitramento aos presidentes das provincias. Entretanto, por atos posteriores a essa lei, o imperador nomeou professores e fixou-lhes os ordenados, sobrepondo-se assim à autoridade dos presidentes.

Após o juramento da Constituição o primeiro ato público que menciona uma gratificação, na administração civil, é o decreto de 18-11-1824, que "concede ao Porteiro da Alfândega da Corte, além do ordenado que já percebe, a gratificação de $400 \$ 000$ Rs." Um decreto de 21 de julho do ano seguinte concede gratificações a numerosos empregados da Alfândega. A já citada lei de 15-10-1827, que fixou entre 200 e $500 \mathrm{mil}$ réis os ordenados dos professores primários, instituiu também, em seu benefício, uma gratificação por tempo de serviço que poderia ser arbitrada até o valor de um terço do salário anual aos que "por mais de doze anos de exercício ininterrupto se tivessem distinguido" etc. A lei de $10^{\circ}$ de outubro de 1828 , sobre a organização das Câmaras Municipais, também pre- via o pagamento, aos servidores dos municípios, de ordenados e gratificações.

Em alguns casos a substituição de um servidor por outro era gratificada. Uma decisão de 27-5-1825 já previa esse tipo de gratificação no caso de um "oficial ou amanuense"... "substituir algum oficial da Administração de Diversas Rendas Nacionais."

\section{DIREITOS E GARANTIAS}

Os direitos que protegem o servidor público contra o arbítrio do Estado não existiam, praticamente, na legislação do tempo de D. Pedro. Nada garantia a um empregado da Nação o seu lugar, salvo, é claro, a compra. Se ele fosse "proprietário" ou vitalício, então seria firme a sua posição. Sob este aspecto geral mudou muito pou$\mathrm{co}$, no primeiro reinado, a precária situação dos empregados civis.

Já foram aqui referidos dois atos que estabeleciam o princípio de igualdade - ou paridade - no serviço público: o que igualava os ordenados dos professores primários (logo depois revogado) e o que estabelecia a igualdade de vencimentos e gratificações entre mestres e mestras.

Uma decisão de 18-2-1825 refere-se ao acesso (promoção) de servidores a cargos de melhor paga. Sob este aspecto é importante o teor do art. 17 do decreto de 5-3-1829, que regulamentou a Administração Geral dos Correios. Diz esse artigo: "Todos os empregados no Correio desta Corte, terão direito a preferência no acesso 
dos empregos, que vagarem, se o merecerem por seu bom serviço, regular conduta e reconhecida aptidão".

A aposentadoria não é uma regra geral e beneficia apenas algumas categorias de servidores, como os magistrados. Quando foram extintos os tribunais da Mesa do Desembargo do Paço e da Mesa da Consciência e Ordens, a respectiva lei (de 22-9-1828) determinou a aposentadoria dos membros dessas duas cortes de Justiça, "conservando o ordenado que venciam", salvo os que tivessem novo emprego. Quanto aos serventuários, dizia a lei (art. $4 .^{\circ}$ ) que venceriam "seus ordenados por inteiro, enquanto não fossem novamente empregados". Isto valia pela disponibilidade remunerada.

No mesmo ano de 1828 e nos seguintes foram aposentados numerosos empregados civis em decorrência de resoluçōes da Assembléia Geral. Em 27 de setembro foi aposentado o escrivão da Alfândega do Tabaco, da Bahia, com o mesmo ordenado da atividade, "não obstante a lei em contrário", como dizia o decreto. Um único decreto de 11-9-1830 aprovou a aposentadoria concedida pela Assembléia a mais de dez servidores.

Foi mencionado acima o tipo de "disponibilidade" concedida pela lei de 22-9-1828 a serventuários dos tribunais por ela extintos. A já aqui citada lei de 15-9-1827, que extinguiu as intendências do ouro, já mandara passar aos escrivães ou meirinhos, proprietários (de seus cargos) ou vitalícios, alvarás de lembrança, para serem providos em outros ofícios de R. Serv. Públ., Brasília, 108 (1): jan/abr. 1973 igual dotação. $E$, enquanto não fossem providos, perceberiam seus ordenados. Mercê idêntica fora concedida aos empregados vitalícios do Tribunal da Junta da Bula da Cruzada pela lei de 29-9-1828, que o extinguiu. Tais atos não se relacionavam, porém, com 0 conceito atual de estabilidade e seu objetivo era 0 de assegurar um status de natureza diferente: se um escrivão fosse "proprietário" do seu cargo, não poderia ser despojado do mesmo. Extinto o cargo, mantinha-se o titular, com seu ordenado, até que outro the fosse concedido.

\section{DEVERES E DISCIPLINAS}

Já vimos que o texto constitucional de 1824 responsabilizava todos os empregados públicos pelos abusos e omissões que cometessem. Um decreto de 18-2-1825 tornou efetiva essa responsabilidade, embora não tivesse sido ainda regulamentada.

A vida funcional precedia a posse no cargo, mas a lei de 24-9-1829 permitiu que os servidores tomassem posse por procuração. Após esse ato, vinha 0 juramento da Constituição, a que estavam obrigados pelo menos os funcionários de média e alta categoria.

Os crimes mais graves que os sorvidores poderiam, no exercício da função pública, cometer, eram previstos na legislação ordinária $e$, em alguns casos, na própria Constituição. Restava à Administração pública o dever de zelar pela disciplina, a assiduidade e a pontualidade dos empregados civis. 
As repartições adotavam um horário cômodo. Os empregados da Biblioteca Imperial trabalhavam das 8 da manhã à uma da tarde (Regimento de 13-9-1824); os servidores da Caixa de Amortização tinham expediente das nove da manhã às duas da tarde "conforme se pratica nas demais repartições públicas" (Regimento de 8-10-1828). O horário dos agentes do Correio, aprovado pela iei de 24-9-1829, era mais rigoroso: das oito ao meio-dia e das três da tarde ao sol posto. Nos domingos e dias santos só trabalhavam de manhã; nas vésperas da saída de navios trabalhavam até as nove da noite, e poderia haver horários extras.

A falta de assiduidade e a impontualidade eram, ao que tudo faz crer, um mal generalizado. Só isto pode explicar o progressivo agravamento das penalidades impostas aos faltosos e impontuais.

Um ato baixado na Secretaria de Estado da Fazenda, em 28-5-1824, determina "que se remeta uma lista nominal dos empregados que faltarem ao expediente da Repartição (Alfândega) para ser publicada". Esse ato exige a presença e a pontualidade dos servidores das outras repartições da Fazenda. A publicação da lista dos faltosos e impontuais servirá "para que todo o empregado remisso sofra a pena de se ver exposto à censura pública".

Em 1827 tomam-se novas medidas para que sejam punidos os funcionários displicentes. Um ato de 31 de outubro daquele ano manda que, nas Repartições, um ajudante anote as faltas e impontualidades para providências posteriores. Em 22 de dezembro sai outro ato determinando o desconto nos vencimentos dos agentes e guardas de consulado faltosos e ainda que, a respeito da assiduidade de tais empregados, se proceda do mesmo modo que se pratica com os oficiais da $\mathrm{Fa}$ zenda (publicação de nomes). Esse ato manda também que se repreendam severamente os impontuais e que se suspendam "imediatamente os que reincidirem e forem contumazes". Já temos portanto os servidores diante de quatro penas disciplinares: a publicação do nome, o desconto em folha, a repreensão e a suspensão.

O Regulamento da Administração Geral dos Correios (Lei de 24-9-1829) mostrou-se mais severo ainda do que a legislação já existente, para com os faltosos e impontuais. Os empregados dos Correios eram obrigados a cumprir os horários das agências sob pena de desconto das faltas e das horas de atraso ou saída antecipada. $\mathrm{Na}$ reincidência o desconto era dobrado. $\mathrm{Na}$ terceira vez os empregados seriam "despedidos imediatamente".

É claro que nem só as faltas e atrasos eram punidos. Os servidores estavam sujeitos ao cumprimento de suas obrigaçōes funcionais $e$ alguns atos do primeiro reinado prevêem puniçōes para os que não as cumprem e para os que as violam. Definindo as "Obrigaçōes Individuais" dos servidores da Biblioteca Imperial, o Já citado Regimento de 1824 prescrevia: "os defeituosos no cumprimento de suas obrigações serão repreendidos". Quanto aos "reincidentes ou incorrigiveis", de- 
les "dará parte o Diretor a S.M. Imperial". Nos Correios o servidor que, chamado a substituir outro, não comparecesse, sem causa atendivel, seria suspenso (art. 19 do Regulamento de 24-9-1829). Pena mais severa impunha-se porém aos que separassem cartas de particulares (certamente para favorecê-los): na primeira vez perderiam a metade de um salário mensal: na segunda, seriam "expulsos de seu emprego".

O mais surpreendente dever imposto aos servidores do Império é talvez o que define o art. $2 .^{\circ}$ do já citado Regimento da Caixa de Amortização (8-10-1828): "Havendo incêndio na casa da Caixa de Amortização, ou nas suas imediações, todos deverão comparecer na mesma casa". O Regimento não explica as razões de tal exigência. Talvez fosse dever dos funcionários apagar o fogo ou então montar guarda ao numerário durante 0 incêndio.

Ainda sobre as faltas ao expediente: elas podiam ser justificadas, pelo menos em alguns casos. Um ato de 29-12-1829, destinado a uma repartição da Marinha, mandava descontar os oficiais (civis) da referida repartição que faltassem (mesmo por doença) se não apresentassem, no dia imediato ao da falta, "certidão do Facultativo". Isso não bastava, porém: teriam de submeter-se, depois, à inspeção do Físico e Cirurgião Mor da Armada.

\section{O CÓDIGO CRIMINAL}

A promulgação do Código Criminal do Império ocorre poucos meses antes da abdicaçăo de Pedro I. Entre os seus dispositivos há alguns que se destinam à proteção dos empregados públicos e à confirmação da sua autoridade. 0 art. 128 manda punir com prisăo, de seis dias a dois meses, quem "desobedecer ao empregado público em ato de exercício de suas funções ou não cumprir as suas ordens legais." o capitulo sobre as prevaricações, abusos e omissões dos empregados públicos (art. 129 e seguintes) é porém muito mais veemente. O Código define os crimes de prevaricação, peita, suborno, concussão, abuso de autoridade ou influência proveniente do emprego, falta de exação e irregularidade de conduta.

As penas impostas aos servidores que violarem a lei penal são, conforme a gravidade do crime cometido, as seguintes: a) suspensão do cargo, que pode ir até três anos; b) multa, proporcional aos prejuizos causados ou ao proveito ilegitimamente auferido; c) inabilidade (inabilitação) temporária para o exercício de função pública; d) inabilidade total para o serviço público; e) prisão, que varia de dois meses a quatro anos. Na maioria dos casos correspondem às infrações, além da pena principal, uma ou duas acessórias.

O Código prevê ainda, fora de capitulo iniciado no art. 129, o crime de peculato, punivel com a perda do emprego, prisão com trabalho por dois meses a quatro anos, e multa de cinco a vinte por cento da quantia ou valor dos efeitos apropriados, consumidos ou extraviados. Também è punivel, mas com penas bem menores, o servidor 
que empresta dinheiros públicos ou faz indevidamente pagamentos antes do tempo.

Não se pode dizer que o Código Criminal do Império, sucessor de leis pe- nais bem mais severas, seja duro com o servidor público. Punindo os delinqüentes, ele exclui da classe os elementos inadaptáveis e contribui para a elevação da sua consciência de responsabilidade.

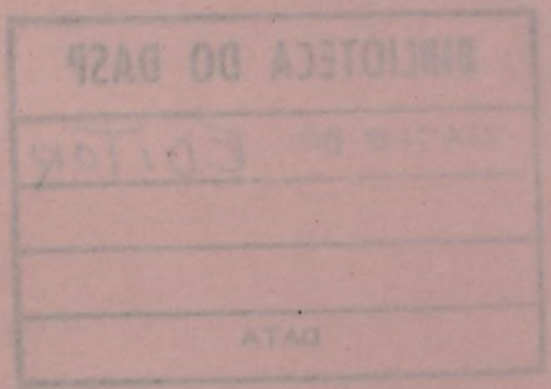

